\title{
Autopsy Findings in a Long-term Survivor With Glioblastoma Multiforme
}

\author{
-Case Report-
}

\author{
Shozo YAMADA, Yuzo Endo*, Takanori HIROSE**, Koji TAKADA, \\ Masaaki USUI, and Mitsuru HARA*
}

\begin{abstract}
Departments of Neurosurgery and ${ }^{*}$ Pathology, Toranomon Hospital, Tokyo; ${ }^{*}$ Department of Pathology, School of Medicine, The University of Tokushima, Tokushima
\end{abstract}

\begin{abstract}
Autopsy detected no tumor tissues in a patient who died 6.5 years after the diagnosis of glioblastoma multiforme. A 54-year-old male developed left hemiparesis one month prior to admission. Computed tomography demonstrated a cystic lesion in the right frontal region with irregular ring-like enhancement. The tumor was extensively removed together with the surrounding tissues followed by irradiation (whole brain $32.4 \mathrm{~Gy}$, local $28.8 \mathrm{~Gy}$ ), and intravenous administration of interferon- $\beta$. Histological examination confirmed the diagnosis of glioblastoma multiforme. He died of accidental head trauma 6.5 years after surgery. Autopsy of the brain detected no evidence of glioblastoma multiforme. The only findings were cerebral edema and hematoma caused by head trauma, as well as histological changes due to radiation damage. This case apparently confirms the histological disappearance of tumor tissue in a long-term survivor with glioblastoma multiforme.
\end{abstract}

Key words: glioblastoma multiforme, interferon, long-term survival, radiation

\section{Introduction}

The prognosis for patients with glioblastoma multiforme is still dismal, despite extensive treatment with surgery, radiotherapy, and chemotherapy. Approximately $90 \%$ of these patients die within 2 years of the histological diagnosis, ${ }^{2,16)}$ and very few survive for 5 years or more. ${ }^{1,3,5,8-10,12,15,22,23)}$ About half of patients with glioblastoma multiforme still die of local tumor recurrence, even if they survive for more than 5 years. ${ }^{\text {II }}$ However, there is little information about whether histological cure is achieved in longterm survivors with glioblastoma multiforme.

We report a unique case of glioblastoma multiforme in which autopsy confirmed the lack of residual or recurrent tumor at 6.5 years after surgery followed by radiotherapy and treatment with interferon- $\beta$ (IFN- $\beta$ ).

Received July 22, 1997; Accepted November 15, 1997

\section{Case Report}

A 54-year-old male received a blood transfusion when he underwent right lower lobectomy for the treatment of pulmonary tuberculosis at age 20 years. He was treated with glycyrrhizin under a diagnosis of liver cirrhosis due to post-transfusion hepatitis $\mathrm{C}$ infection beginning in December 1984 until June 1988. In early April 1988, he began to complain of weakness of the left foot, and developed unsteady gait as well as weakness of the left arm. He was admitted to our department on June 10, 1988, because cranial computed tomography (CT) revealed an enhancing cystic lesion in the right frontal region with surrounding edema (Fig. 1 left). On admission, he showed slight left hemiparesis, but could walk and take care of most of his needs (Karnofsky score 70).

Right frontal craniotomy was performed on July 4 , 1988. A large cyst $(2.5 \mathrm{~cm}$ in diameter) was found in the subcortex of the upper frontal lobe. Approximately $11 \mathrm{ml}$ of yellowish serous fluid was aspirated by puncturing the cyst. When the brain was incised and the cyst was opened, the cyst wall consisted of reddish-gray, soft tumor tissue. This thin cyst wall 

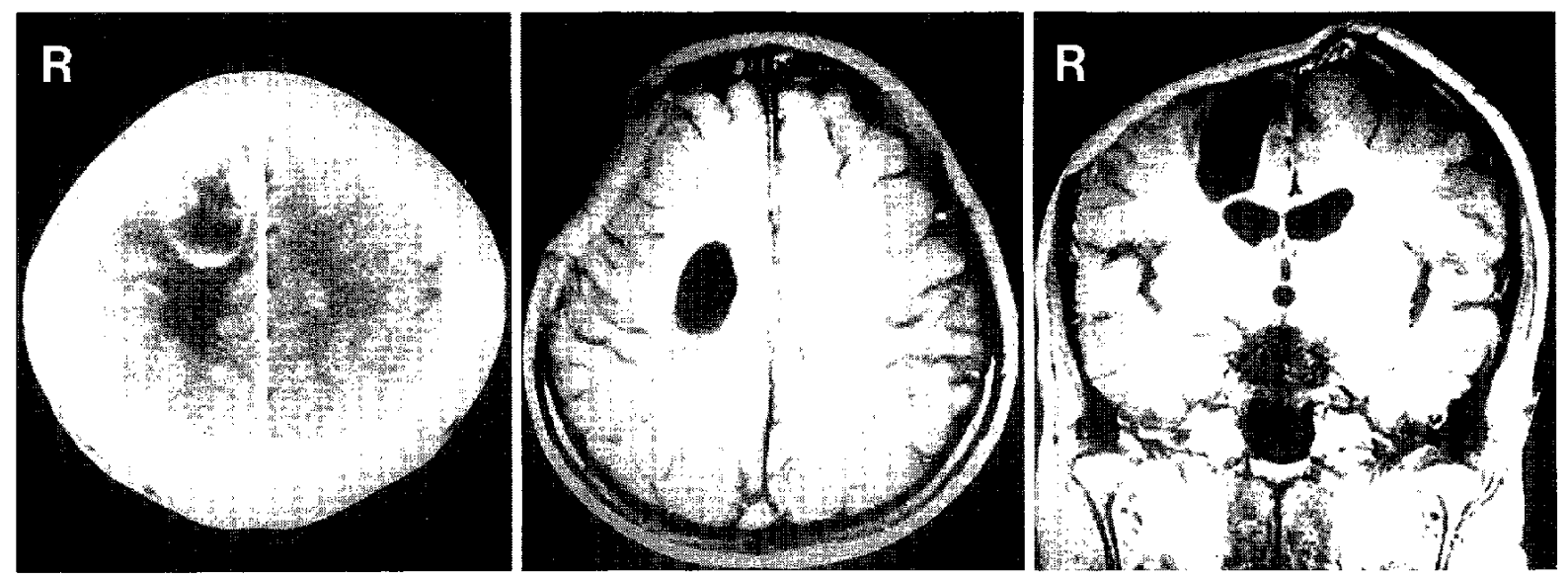

Fig. 1 Preoperative computed tomography scan of the head (left) showing an enhanced right frontal mass with surrounding cerebral edema. Axial (center) and coronal (right) $T_{1}$-weighted magnetic resonance images with gadolinum obtained 5 years postoperatively, demonstrating a lowintensity area in the right frontal region without enhancement or perifocal cerebral edema.

was dissected from the surrounding white matter and was excised as completely as possible using a bipolar coagulator and suction. In addition, the white matter surrounding the cyst wall was aspirated for a few millimeters, because the tumor border seemed to be indistinct in some areas.

Histological examination confirmed the diagnosis of glioblastoma multiforme as the tumor showed increased cellularity with marked cellular and nuclear pleomorphism, many mitoses, and some areas of necrosis that were occasionally associated with pseudopalisading. Endothelial cell proliferation was also found. There were no areas of low grade glioma in the resected tissues (Fig. 2A-C). Reticulin staining was positive around the blood vessels, but was negative around individual tumor cells. Many tumor cells showed immunopositivity for glial fibrillary acidic protein, but were negative for vimentin (Fig. 2D). In addition, the percentage of MIB-1 positivity was calculated as $17.9 \pm 1.4 \%$ (mean $\pm \mathrm{SE}$ ) by counting 1000 tumor cells in each of three randomly selected areas (Fig. 2E).

Postoperatively, he was oriented but showed moderate left hemiparesis for the initial 3 weeks. However, there was gradual improvement and he could walk and perform daily activities without assistance 7 weeks after surgery. He received irradiation with a total dose of $61.2 \mathrm{~Gy}$ (whole brain 32.4 $\mathrm{Gy}$, local $28.8 \mathrm{~Gy}$ ) in 45 fractions, and also received intravenous IFN- $\beta$ (Toray Industries, Inc., Tokyo) at a dose of 3,000,000 U/day twice a week from postoperative day 13 to discharge. IFN- $\beta$ was subsequently given every 2 weeks until he died. He was discharged on September 3, 1988 with very slight weakness of the left upper and lower extremities (Karnofsky score 80). He returned to work as a researcher at a steel company until February 1993 when his left hemiparesis slowly became worse. However, there was no evidence of tumor recurrence and the rest of the brain appeared normal on magnetic resonance imaging (Fig. 1 center, right). Although he could walk with the aid of a $T$ cane and short leg brace, he was unable to commute to work. In June 1994 he became very slow and developed slight dementia. On October 29, 1994 he fell at home and injured his occipital region. On emergency admission, he was confused, delusional, and had left hemiparesis. CT revealed intracerebral hemorrhage with brain swelling and subarachnoid hemorrhage associated in the left suboccipital region. His condition deteriorated rapidly and he died on November 10,1994 , aged 59 years, and 6.5 years after the removal of the brain tumor.

Autopsy was limited to the central nervous system. The brain weighed $1590 \mathrm{~g}$ due to severe brain swelling, especially of the brainstem and cerebellum. Diffuse subarachnoid hemorrhage was found in the right supracerebellar cistern and intracerebral hematoma in the right centrum semiovale in the parieto-occipital region. The intracerebral hematoma had ruptured into the right lateral ventricle with downward displacement of the thalamus and putamen on the right. In addition, uncal herniation was present and the midbrain was severely compressed and distorted. The brain swelling and intracerebral hematoma secondary to head trauma were considered to be the direct cause of death.

Extensive histological examination of the right 


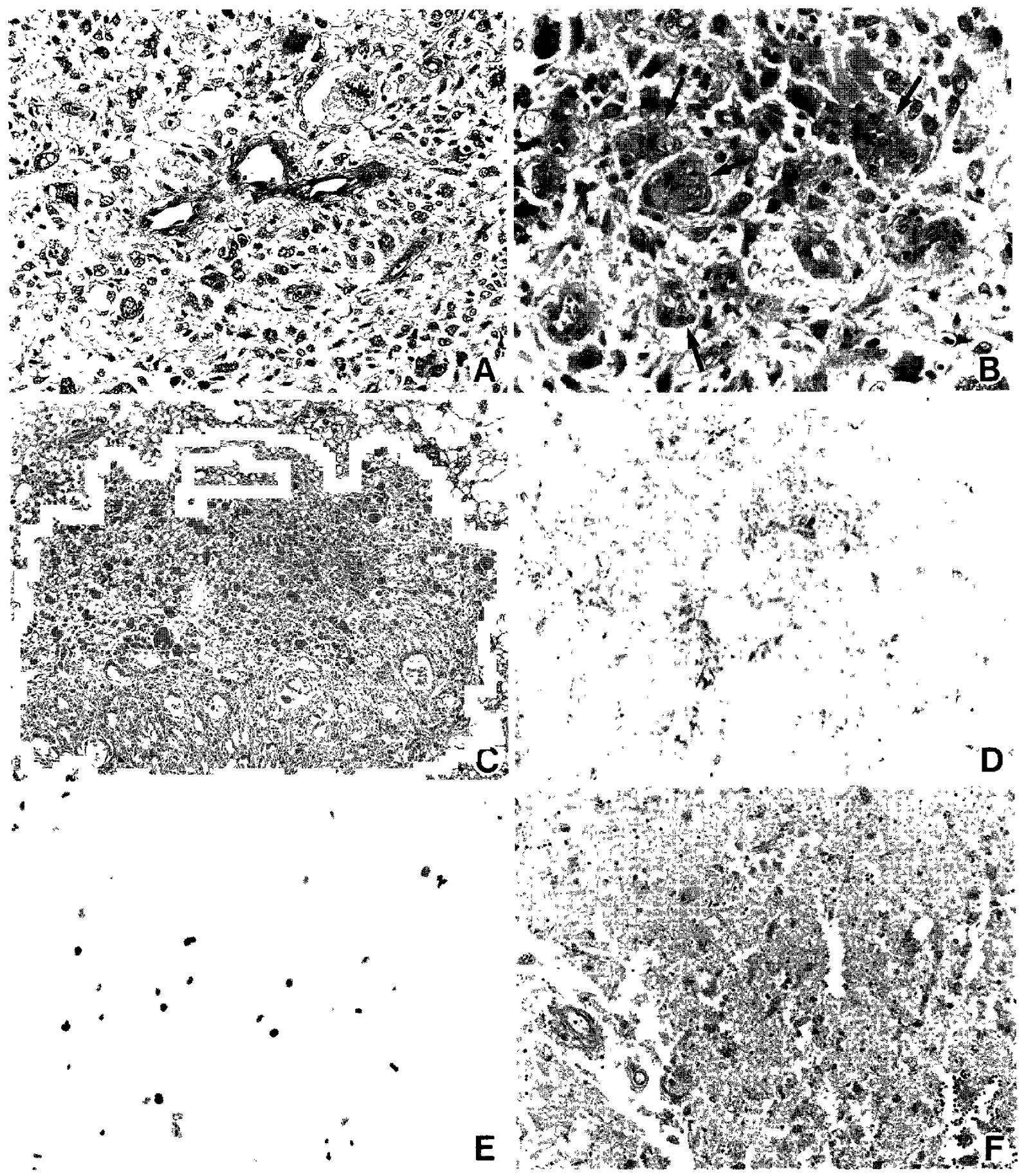

Fig. 2 Photomicrographs of the tumor specimen showing anaplastic, pleomorphic tumor cells with mitotic figures and multinucleated giant cells containing hyperchromatic irregular nuclei (A: HE stain, $\times 240$ ), capillary endothelial proliferation (arrows) (B: HE stain, $\times 260$ ), necrosis and associated pseudopalisading (C: HE stain, $\times 150$ ), and immunostaining for glial fibrillary acidic protein (D: $\times 200)$ and MIB-1 (E: $\times 200)$. Photomicrograph of tissue surrounding the original tumor site showing significant necrosis without infiltration, proliferation, or anaplastic tumor cells, and hyaline change of the small vessels (F: HE stain, $\times 120$ ). 
frontal lobe, including the operative field and its surroundings, failed to find any evidence of residual or recurrent glioblastoma multiforme. Instead, there was significant necrosis and degeneration of nerve fibers as well as slight hyaline change in the small vessels (Fig. 2F). No evidence of glioblastoma multiforme was found in any brain region examined, including the dura, brainstem, cerebellum, and pituitary gland.

\section{Discussion}

Long-term survival of patients with glioblastoma multiforme for more than 10 years is rare. ${ }^{1,5,8,9,15,17,22,23)}$ Death from recurrent disease is unusual in such long-term survivors based on an analysis of 13 patients who lived for more than 4 years after diagnosis. ${ }^{22)}$ However, clinical "cure" was not confirmed histologically in these patients, but was based on the unexpected longevity or on neuroimaging findings showing no evidence of residual tumor or regrowth. ${ }^{8)}$ Autopsy confirmed the presence of glioblastoma multiforme in two patients who survived 9.8 and 6.5 years after the initial operation. ${ }^{12)}$ This suggests that the tumor can still recur even in patients who have survived more than 5 years, or else that rare patients may survive for a long period despite the presence of residual tumor after surgery. The significant difference in the duration of survival depending on the histological appearance of glioblastoma multiforme is well known. ${ }^{201}$ None of the patients with "pure" glioblastoma multiforme in one series lived for over 1 year, whereas in another series $27 \%$ of patients with astrocytoma and glioblastomatous changes survived for 2 years after surgery, compared to only $10 \%$ of patients with "pure" glioblastoma multiforme. ${ }^{18,21]}$ Many cases of socalled circumscribed glioblastoma multiforme, especially those with a long survival time, may not be glioblastoma multiforme at all, but actually other types of malignant or regressively altering gliomas, or else primary brain sarcomas. ${ }^{7)}$ In contrast, our patient had a glioblastoma multiforme with typical histology and we could exclude other types of malignant glioma, including anaplastic astrocytoma, astroblastoma, giant cell glioblastoma, and pleomorphic xanthoastrocytoma. The percentage of MIB-1 immunopositive cells also corresponded to that reported for glioblastoma multiforme. ${ }^{13)}$ Our case was considered to be "pure" or "primary" glioblastoma multiforme, because no histological evidence of low grade glioma was found in the tumor specimen. Therefore, our case seems to confirm the histological disappearance of tumor tissue in a long-term survivor.
The favorable prognostic factors contributing to long-term survival of patients with glioblastoma multiforme include young age, ${ }^{3,10,14,17,20,22)}$ a high preoperative performance status, ${ }^{3,4,14,20,22)}$ lobar tumor location, ${ }^{4,201}$ tumor calcification, ${ }^{201}$ cyst formation, ${ }^{20]}$ aggressive surgical excision, ${ }^{1,3,5,10)}$ and adequate radiotherapy, ${ }^{4,14,22]}$ but there have been contradictory findings in different studies and no features have consistently predicted a favorable outcome.

In our patient, early postoperative CT suggested that the tumor had been removed completely due to its relatively well circumscribed nature as a cystic frontal mass. The postmortem histological findings (significant necrosis, diffuse degeneration of nerve fibers, and hyaline change of small vessels) corresponded to those of radiation damage, suggesting that radiotherapy may have been the other major factor leading to cure. Similarly, significant necrosis without any infiltrating, proliferating, or viable tumor masses were found at the original site in patients who died after fast neutron radiation therapy. ${ }^{6)}$ The slowly progressive weakness and dementia that affected our patient about 5 years after radiotherapy may also have been due to radiation damage to the normal brain. IFN- $\beta$ has been used in Japan as a biological response modifier and is useful for treating malignant astrocytoma. ${ }^{11]}$ Several patients have survived more than 5 years without neuroradiological tumor recurrence after brain irradiation followed by IFN- $\beta$ administration every 2 weeks after surgery. ${ }^{19)}$ Therefore, IFN- $\beta$ may also have contributed to the long-term survival of our patient, although there is no definite evidence.

\section{References}

1) Bucy PC, Oberhill HR, Siqueira MD, Zimmerman HM, Jelsma RK: Cerebral glioblastomas can be cured! Neurosurgery 16: 714-717, 1985

2) Burger PC, Vogel FS, Green SB, Strike TA: Glioblastoma multiforme and anaplastic astrocytoma: Pathologic criteria and prognostic implications. Cancer 56: 1106-1111, 1985

3) Chandler KL, Prados MD, Malec M, Wilson CB: Long-term survival in patients with glioblastoma multiforme. Neurosurgery 32: 716-720, 1993

4) Coffey RJ, Lunsford LD: Factors determining survival of patients with malignant gliomas diagnosed by stereotactic biopsy. Appl Neurophysiol 50: 183187, 1987

5) Elvidge AR, Barone BM: Long-term postoperative survival in two cases of glioblastoma multiforme. J Neurosurg 22: 382-386, 1965

6] Griffin TW, Davis R, Laramore G, Hendrickson F: Fast neutron radiation therapy for glioblastoma multiforme. Am J Clin Oncol 6: 661-667, 1983

7) Gullotta F, Bettag W: Zur frage der langeren uberle- 
benzeit bei glioblastomen. Acta Neurochir (Wien) 16: 122-128, 1966

8) Hatanaka H, Sano K, Kitamura K, Fukui M, Mogami $\mathrm{H}$, Ushio $\mathrm{Y}$, Kuwabara $\mathrm{T}$, Kyuma $\mathrm{Y}$, Inaba $\mathrm{Y}$, Hiratsuka H, Suzuki J, Katakura R, Takakura K, Handa $\mathrm{H}$, Yamashita J: CT findings in patients with gliomas, surviving more than 10 years. Neurochirurgia (Stuttg) 27: 106-110, 1984

9) Imperato JP, Paleologos NA, Vick NA: Effects of treatment on long-term survivors with maligmant astrocytomas. Ann Neurol 28: 818-822, 1990

10) Jelsma R, Bucy PC: The treatment of glioblastoma multiforme of the brain. J Neurosurg 27: 388-400, 1967

11) Nagai $M$, Arai $T$ : Clinical use of interferon in malignant brain tumours. Neurosurg Rev 7: 55-64, 1984

12) Netsky MG, August B, Fowler $W$ : The longevity of patients with glioblastoma multiforme. J Neurosurg 7: 261-269, 1950

13) Onda K, Davis RL, Shibuya M, Wilson CB, Hoshino $\mathrm{T}$ : Correlation between the bromodeoxyuridine labeling index and the MIB-1 and Ki-67 proliferating cell indices in cerebral gliomas. Cancer 74: 1921-1926, 1994

14) Phuphanich S, Ferrall S, Greenberg H: Long-term survival in malignant glioma. J Fla Med Assoc 80: 181184, 1993

15) Rutz HP, de Tribolet N, Calmes JM, Chapuis G: Longterm survival of a patient with glioblastoma and Turcot's syndrome. J Neurosurg 74: 813-815, 1991

16) Salcman M: Survival in glioblastoma: Historical per- spective. Neurosurgery 7: 435-439, 1980

17) Salford LG, Brun A, Nirfalk S: Ten-year survival among patients with supratentorial astrocytomas grade III and lV. J Neurosurg 69: 506-509, 1988

18) Scherer HL: Cerebral astrocytomas and their derivatives. Am J Cancer 40: 159-198, 1940

19) Shitara N, Nakamura H, Genka S, Takakura K: [Efficacy of interferon- $\beta$ and interleukin-2 as cytokines for malignant brain tumor treatment]. Gan To Kagaku Ryoho 14: 3235-3244, 1987 (Jpn, with Eng abstract)

20) Takeuchi K, Hoshino K: Statistical analysis of factors affecting survival after glioblastoma multiforme. Acta Neurochir (Wien) 37: 57-73, 1977

21) Taveras JM, Thompson HG Jr, Pool JL: Should we treat glioblastoma multiforme? AJR Am J Roentgenol 87: 473-479, 1962

22) Vertosick FT Jr, Selker RG: Long-term survival after the diagnosis of malignant glioma: A series of 22 patients surviving more than 4 years after diagnosis. Surg Neurol 38: 359-363, 1992

23) Zareba A, Wistawski J: [Survival over 10 years after operation for glioblastoma multiforme: Report on two cases]. Neurol Neurochir Pol 23: 368-372, 1989 (Pol, with Eng abstract]

Address reprint requests to: S. Yamada, M.D., Department of Neurosurgery, Toranomon Hospital, 2-2-2 Toranomon, Minato-ku, Tokyo 105-0001, Japan. 